\title{
Sensitization of Candida albicans biofilms to various antifungal drugs by cyclosporine $\mathrm{A}$
}

\author{
Ravikumar B Shinde, Nitin M Chauhan, Jayant S Raut and Sankunny M Karuppayil
}

\begin{abstract}
Background: Biofilms formed by Candida albicans are resistant towards most of the available antifungal drugs. Therefore, infections associated with Candida biofilms are considered as a threat to immunocompromised patients. Combinatorial drug therapy may be a good strategy to combat C. albicans biofilms.

Methods: Combinations of five antifungal drugs- fluconazole (FLC), voriconazole (VOR), caspofungin (CSP), amphotericin B (AmB) and nystatin (NYT) with cyclosporine A (CSA) were tested in vitro against planktonic and biofilm growth of $C$. albicans. Standard broth micro dilution method was used to study planktonic growth, while biofilms were studied in an in vitro biofilm model. A chequerboard format was used to determine fractional inhibitory concentration indices (FICI) of combination effects. Biofilm growth was analyzed using XTT-metabolic assay.
\end{abstract}

Results: MICS of various antifungal drugs for planktonic growth of $C$. albicans were lowered in combination with CSA by 2 to 16 fold. Activity against biofilm development with FIC indices of $0.26,0.28,0.31$ and 0.25 indicated synergistic interactions between FLC-CSA, VOR-CSA, CSP-CSA and AmB-CSA, respectively. Increase in efficacy of the drugs FLC, VOR and CSP against mature biofilms after addition of $62.5 \mu \mathrm{g} / \mathrm{ml}$ of CSA was evident with FIC indices $0.06,0.14$ and 0.37 , respectively.

Conclusions: The combinations with CSA resulted in increased susceptibility of biofilms to antifungal drugs. Combination of antifungal drugs with CSA would be an effective prophylactic and therapeutic strategy against biofilm associated C. albicans infections.

Keywords: Antifungal, Biofilms, Candida albicans, Calcineurine, Drug combination, Cyclosporine A, Drug resistance, Synergism

\section{Background}

Candida albicans continues to be the most common fungal pathogen and a major cause of high morbidity and mortality among immunocompromised patients [1-3]. Candida readily forms biofilms on host tissues and medical devices implanted in the patient's body [4]. Options of the antifungal drugs available for the treatment of systemic and invasive candidiasis are restricted to polyenes, allylamines, azoles and echinocandin class of molecules [5]. Side effects due to toxicity of the drugs and emergence of drug resistant strains have put limitations on the effective use of these drugs [5-7]. Moreover, biofilms show dramatically different properties from their

\footnotetext{
* Correspondence: prof.karuppayil@gmail.com

DST-FIST Sponsored School of Life Sciences, SRTM University, Nanded, MS 431 606, India
}

\section{Biomed Central}

planktonic counterparts, such as increased resistance to antimicrobial agents, multiple drug resistance and tolerance to host defenses. Susceptibility studies have revealed that biofilms formed by C. albicans may be up to 2000 times more resistant to antifungal drugs than the planktonic cells $[4,8,9]$. In this scenario, there is a need for new strategies to combat fungal infections, especially biofilm associated infections. Efforts are being done to explore the efficacy of combination therapy in the treatment of infections that are refractory towards antifungal drugs [10]. Combinations of antifungal drugs from different classes are being studied against $C$. albicans. Combining azoles with flucytosine was found to result in either indifference or antagonism [11,12]. Also, combinations of $\mathrm{AmB}$, azoles and echinocandin with azoles/ polyenes did not show significant antifungal activity [13]. Not many 
studies are available which have discussed efficacy of drug combinations against biofilm growth of C. albicans [14]. Interestingly, results of combination against planktonic cells may not always match with that of the biofilm forms. For example, combination of FLC and AmB has synergistic effects on planktonic growth of $C$. albicans but does not alter activity of $\mathrm{AmB}$ against biofilms $[15,16]$. FLC with CSP have antagonistic effects against biofilms, unlike its planktonic counterpart [16,17]. This suggests the need for drug combination studies in biofilm settings. Various drugs including inhibitors of multidrug efflux transporters, antimicrobial agents, membrane active compounds, are being screened for their combined activity with known antifungal drugs [18]. It was found that growth of planktonic cells of $C$. albicans is sensitive to the calcineurine inhibitors FK 506 and cyclosporine A in combination with fluconazole [17]. Calcineurine is a $\mathrm{Ca}^{2+}$ - calmodulin activated protein phosphatase, which plays an important role in multiple aspects of fungal physiology including cation homeostasis, morphogenesis, antifungal drug resistance and virulence. Recently, it was revealed that $C$. albicans biofilms are resistant to FLC as well as CSA, however significantly sensitive to combination of the two [19]. Surprisingly, efficacy of CSA in combination with other antifungal drugs has not been studied. In our systematic study, for the first time we have analyzed the effects of CSA combination with five antifungal drugs (which belong to three classes) FLC \& VOR (azoles), AmB \& NYT (polyenes) and CSP (echinocandins). Efficacy of these combinations against planktonic and biofilm growth of C. albicans is discussed.

\section{Methods}

\section{Cultures and antifungal agents}

A standard strain of Candida albicans ATCC 90028 was obtained from the Institute of Microbial Technology, Chandigarh, India. Culture was maintained on yeast extract peptone dextrose (YPD) agar slants at $4{ }^{\circ} \mathrm{C}$ (All the media components were purchased from HiMedia laboratories Pvt. Ltd. Mumbai, India). Antifungal agents, Fluconazole (FLC) (Forcan, Cipla Ltd., India), Voriconazole (VOR) (Vonaz, United Biotech Pvt. Ltd., India), Caspofungin (CSP) (Cancidas ${ }^{\mathrm{TM}}$, Merck \& Co. Inc., USA), Amphotericin B (AmB) (Lyka Pharm. Pvt. Ltd., India), Nystatin (NYT) (HiMedia, Pvt. Ltd., India), Cyclosporine A (CSA) (Sun Pharm. India Ltd., India) were obtained from local market.

\section{Medium and culture conditions}

Activation of culture was done by inoculating a single colony from YPD agar plate (yeast extract $1 \%$, peptone $2 \%$, dextrose $2 \%$, agar $2 \%$ ) into $50 \mathrm{ml} \mathrm{YPD} \mathrm{broth} \mathrm{in} \mathrm{a}$ $250 \mathrm{ml}$ conical flask. The flasks were incubated at $30{ }^{\circ} \mathrm{C}$ at $100 \mathrm{rpm}$ on an orbital shaking incubator for $24 \mathrm{~h}$.
Cells were harvested by centrifugation at $2000 \times g$ and washed thrice with $0.1 \mathrm{M}$ phosphate buffer saline (PBS), $\mathrm{pH}$ 7.4. Final cell number was adjusted to $1 \times 10^{7}$ cells $/ \mathrm{ml}$ and used for experiments.

\section{Susceptibility of planktonic cells to antifungal drugs}

The susceptibility study was carried out by the standard broth micro dilution method, as per CLSI guidelines [20]. Briefly, various concentrations of drugs in the range $0.5 \mu \mathrm{g} / \mathrm{ml}$ to $32 \mu \mathrm{g} / \mathrm{ml}$ for FLC, $0.0625 \mu \mathrm{g} / \mathrm{ml}$ to $8 \mu \mathrm{g} / \mathrm{ml}$ for VOR, CSP and AmB, $0.125 \mu \mathrm{g} / \mathrm{ml}$ to $16 \mu \mathrm{g} / \mathrm{ml}$ for NYT and 7.75 to $500 \mu \mathrm{g} / \mathrm{ml}$ for CSA, were prepared in RPMI-1640 medium pH 7.0, (with L-glutamine, without sodium bicarbonate, buffered with $165 \mathrm{mM}$ MOPS). (HiMedia laboratories Pvt. Ltd. Mumbai, India). Drugs were used in water soluble forms; hence the stock solutions were prepared freshly in RPMI medium. A series of concentrations were prepared in the 96 well plates by double dilution. Wells without drugs served as a control. Inoculum of $1 \times 10^{3}$ cells $/ \mathrm{ml}$ was added to each well and the plates were incubated at $37{ }^{\circ} \mathrm{C}$ for 48 hours and read spectrophotometrically at $620 \mathrm{~nm}$ using a microplate reader (Multiskan EX, Thermo Electron Corp., USA). The lowest concentration of the drugs which caused fifty percentage reduction in the absorbance compared to that of control, was considered as minimum inhibitory concentration (MIC); except for $\mathrm{AmB}$ where $>70 \%$ inhibition of growth was considered MIC endpoint.

\section{Chequerboard format for determination of $\mathrm{FICI}$}

Dilutions of individual drugs and their different combinations were prepared in a chequerboard format as per standard methodology [18]. A two dimensional array of serial concentrations of test compounds were used for preparation of drug dilutions. $100 \mu \mathrm{l}$ of cell suspension was added to each well and the micro plates were incubated at $35{ }^{\circ} \mathrm{C}$. After $48 \mathrm{~h}$ of incubation, absorbance was read using microplate reader at $620 \mathrm{~nm}$. MIC for growth was determined as the concentrations of antifungal drugs where $50 \%$ reduction in the absorbance compared to that of control was obtained. FIC indices were calculated with a little modification. The FICI model is expressed as: $\Sigma \mathrm{FIC}=\mathrm{FIC}_{\mathrm{A}}+\mathrm{FIC}_{\mathrm{B}}$. Where, $\mathrm{FIC}_{\mathrm{A}}=$ (MIC of drug $\mathrm{A}$ in combination / MIC of drug $\mathrm{A}$ alone) $\mathrm{FIC}_{\mathrm{B}}=(\mathrm{MIC}$ of drug $\mathrm{B}$ in combination / MIC of drug $B$ alone) When the value of $\Sigma F I C \leq 0.5$, it is the synergism and when $\Sigma F I C>4$ it is known as the antagonism. A $\Sigma F I C>0.5$ but $\leq 4$ is considered as indifference $[21,22]$.

\section{Biofilm formation and drug susceptibility}

For biofilm formation, $100 \mu \mathrm{l}$ of the cell suspension $\left(1 \times 10^{7}\right.$ cells $/ \mathrm{ml}$ in PBS $)$ was added to each well of 96 well micro plates. Plates were incubated at $37{ }^{\circ} \mathrm{C}$ on an 
orbital shaker for 90 minutes of adhesion phase. Wells were washed with sterile PBS to remove non-adhered cells and $200 \mu \mathrm{l}$ of RPMI-1640 medium was added to adhered cells. To carry out susceptibility of biofilm development, medium containing various concentrations of the drugs was added at the zero hour of biofilm formation i.e. immediately after adhesion phase and the plates were incubated at $37{ }^{\circ} \mathrm{C}$ for 48 hours, at $100 \mathrm{rpm}$ in an orbital shaker. While, to analyze the effects on mature biofilms, medium with a range of drug concentrations was added to the 24 hour old biofilms. The plates were further incubated for 48 hours at $37{ }^{\circ} \mathrm{C}$ [23]. Density of the cells survived in biofilm forms was analyzed through metabolic activity in XTT-formazan reduction assay.

\section{Biofilm quantitation by XTT assay}

Biofilm formation was quantitated using XTT [i.e. 2, 3-bis (2-methoxy-4-nitro-sulfophenyl)-2H-tetrazolium-5-carboxanilide] (Sigma-Aldrich, India) reduction assay [23]. Briefly, XTT solution was prepared by mixing $1 \mathrm{mg} / \mathrm{ml}$ XTT salt in PBS and stored at $-20{ }^{\circ} \mathrm{C}$. Prior to use, menadione solution prepared in acetone (Sigma-Aldrich, India) was added to XTT to a final concentration of $4 \mu \mathrm{M}$. The wells containing biofilms were washed with PBS to remove non adhered cells and incubated for 5 hours in $100 \mu$ of XTTmenadione solution in dark, at $37^{\circ} \mathrm{C}$ at $100 \mathrm{rpm}$. The color formation by water soluble formazan product was measured at $450 \mathrm{~nm}$ using a microplate reader (Multiskan EX, Thermo Electron Corp., USA). Wells without biofilms served as a blank.

\section{Results}

Cyclosporine $A$ is synergistic with antifungal drugs against planktonic forms

Planktonic growth of C. albicans was susceptible to different antifungal drugs at varying concentrations. MICs of FLC, VOR, CSP, AmB and NYT were found at $0.5 \mu \mathrm{g} / \mathrm{ml}, 0.125 \mu \mathrm{g} / \mathrm{ml}, 0.25 \mu \mathrm{g} / \mathrm{ml}, 0.5 \mu \mathrm{g} / \mathrm{ml}$ and $1 \mu \mathrm{g} / \mathrm{ml}$, respectively (Table 1 , Figure 1 ). CSA alone showed significant $(\geq 50 \%)$ inhibition of planktonic growth of C. albicans at concentration of $250 \mu \mathrm{g} / \mathrm{ml}$ (data not shown). Concentrations lower than MIC did not affect $C$. albicans, and $>80 \%$ growth was seen in presence of 62.5 and $125 \mu \mathrm{g} / \mathrm{ml} \mathrm{CSA} \mathrm{(Figure} \mathrm{1).} \mathrm{A} \mathrm{signifi-}$ cant decrease in MICs of antifungal drugs was observed when cells were treated in presence of $62.5 \mu \mathrm{g} / \mathrm{ml}$ of CSA. For example, MIC of FLC in combination with CSA was found to be $0.031 \mu \mathrm{g} / \mathrm{ml}$ i. e. sixteen times less than that of fluconazole alone. FIC index for the combination was calculated to be 0.24 , which indicated that combination is synergistic. In presence of $125 \mu \mathrm{g} / \mathrm{ml}$ of CSA, fluconazole activity was increased by 64 times (Figure 1A). VOR concentration required to inhibit C. albicans in presence of $62.5 \mu \mathrm{g} / \mathrm{ml}$ CSA was four times less than MIC of VOR alone (Figure 1B). FIC index for this combination was calculated to be 0.37 . While, $125 \mu \mathrm{g} / \mathrm{ml}$ of CSA increased the fluconazole activity by eight fold. Addition of 62.5 and $125 \mu \mathrm{g} / \mathrm{ml}$ of CSA lowered MIC of CSP to 0.063 and $0.008 \mu \mathrm{g} / \mathrm{ml}$, respectively, showing 4 and 32 fold increase in susceptibility of C. albicans (Figure $1 C$ ). This combination was found highly synergistic with the FIC index of 0.24 . Combination of $62.5 \mu \mathrm{g} / \mathrm{ml}$ of CSA was not effective; however AmB in presence of $125 \mu \mathrm{g} / \mathrm{ml}$ of CSA inhibited the growth at a concentration 32 times lesser than MIC of $\mathrm{AmB}$ alone (Figure 1D). In presence of 62.5 and $125 \mu \mathrm{g} / \mathrm{ml} \mathrm{CSA}$, MIC of NYT for C. albicans growth was obtained at 0.25 and $0.031 \mu \mathrm{g} / \mathrm{ml}$, respectively. Combination of NYT and CSA was 4 to 32 times efficient than that of NYT alone (Figure 1E).

\section{Biofilm development was sensitive to antifungal-CSA combinations}

Biofilm development was found resistant to FLC and significant inhibition was obtained only at very high concentration (i. e. $512 \mu \mathrm{g} / \mathrm{ml}$ ). Also, VOR concentration required to inhibit biofilm formation was 16 fold high than the MIC for planktonic growth. CSA showed MIC for biofilms at $500 \mu \mathrm{g} / \mathrm{ml}$ concentration, whereas 62.5 and $125 \mu \mathrm{g} / \mathrm{ml}$ did not have any effect on biofilm development. FLC- CSA combination was found highly synergistic against biofilm development. Addition of $62.5 \mu \mathrm{g} / \mathrm{ml}$ of

Table 1 MICs of antifungals alone and in combination with CSA against C. albicans

\begin{tabular}{|c|c|c|c|c|c|c|}
\hline \multirow[t]{3}{*}{ Name of Drug } & \multicolumn{6}{|c|}{ Minimum Inhibitory Concentration $(\mu \mathrm{g} / \mathrm{ml})$} \\
\hline & \multicolumn{2}{|c|}{ Planktonic cells $^{a}$} & \multicolumn{2}{|c|}{ Biofilm development ${ }^{\text {b }}$} & \multicolumn{2}{|c|}{ Mature biofilms ${ }^{b}$} \\
\hline & Drug alone & Drug $+62.5 \mu \mathrm{g} / \mathrm{ml} \mathrm{CSA}$ & Drug alone & Drug $+62.5 \mu \mathrm{g} / \mathrm{ml} \mathrm{CSA}$ & Drug alone & Drug $+62.5 \mu \mathrm{g} / \mathrm{ml} \mathrm{CSA}$ \\
\hline FLC & 0.5 & 0.031 & 512 & 1 & 1024 & 2 \\
\hline VOR & 0.125 & 0.031 & 2 & 0.063 & 4 & 0.061 \\
\hline CSP & 0.25 & 0.063 & 0.5 & 0.063 & 1 & 0.125 \\
\hline AmB & 0.5 & 0.5 & 0.5 & 0.031 & 0.5 & 0.5 \\
\hline NYT & 1 & 0.25 & 3 & 3 & 3 & 3 \\
\hline
\end{tabular}

${ }^{\mathbf{a}}$ Measured in terms of absorbance of cell density ${ }^{\mathbf{b}}$ Measured in terms of percentage RMA obtained in XTT assay. 


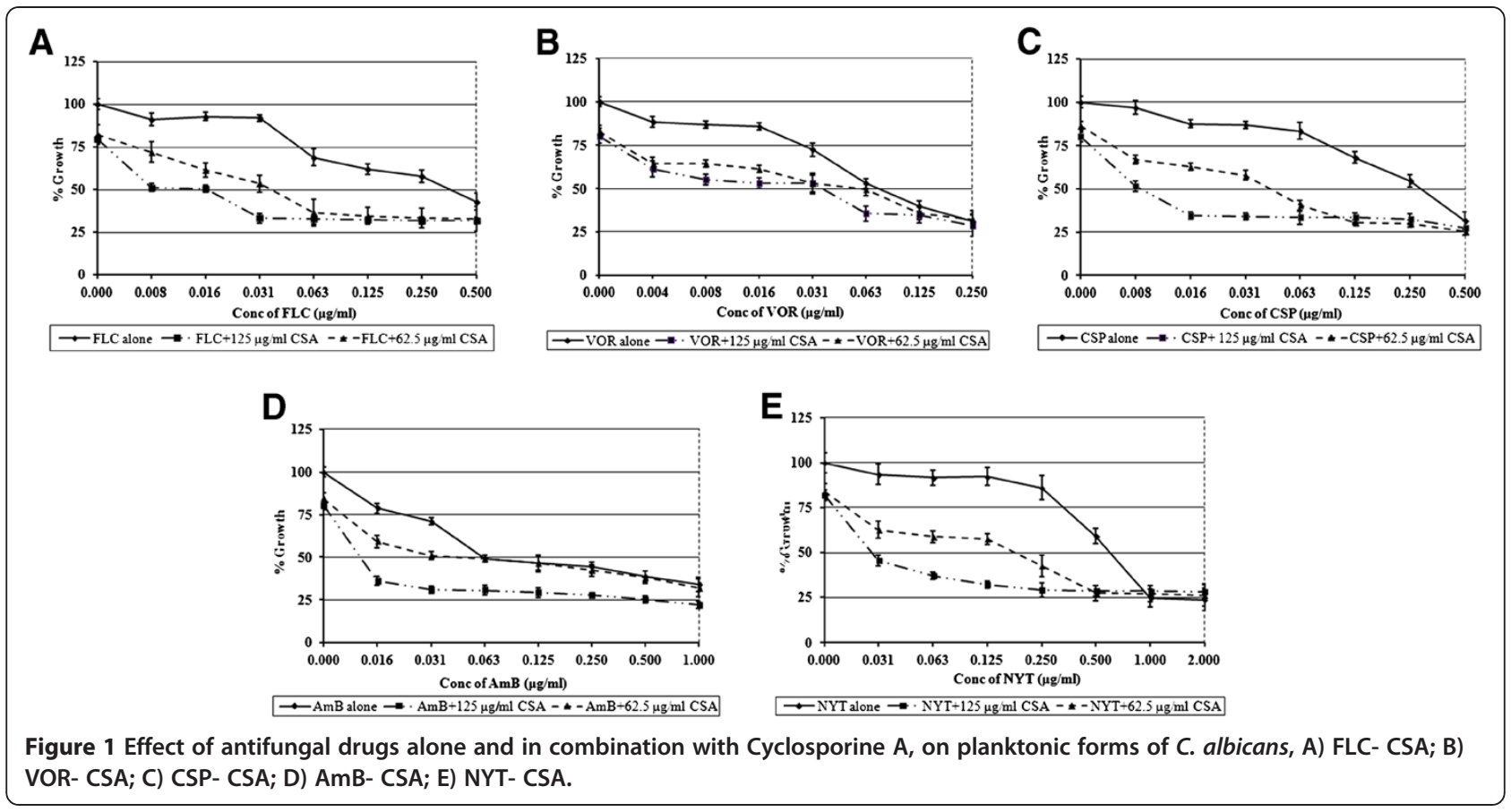

CSA sensitized the cells to fluconazole and MIC was achieved at $1 \mu \mathrm{g} / \mathrm{ml}$ (Table 1, Figure 2A). The FIC index for the combination was 0.26. In combination with $62.5 \mu \mathrm{g} / \mathrm{ml}$ of CSA, MIC of VOR was brought down to the $0.063 \mu \mathrm{g} / \mathrm{ml}$ (Figure $2 \mathrm{~B}$ ), with the FIC index of $0.28 \mathrm{in}$ dicating the synergism. While, addition of $125 \mu \mathrm{g} / \mathrm{ml}$ CSA showed decrease in VOR MIC for biofilm development i. e. at $0.016 \mu \mathrm{g} / \mathrm{ml}$ concentration. Inhibition of biofilm development was obtained at CSP concentration of $0.5 \mu \mathrm{g} / \mathrm{ml}$, while combination with 62.5 and $125 \mu \mathrm{g} /$ $\mathrm{ml}$ of CSA caused eight folds decrease in the MIC to make it $0.063 \mu \mathrm{g} / \mathrm{ml}$ (Figure $2 \mathrm{C}$ ). A synergistic interaction between these two drugs was evident with FICI of 0.31. The combination with CSA resulted in sixteen fold decrease in concentration of the $\mathrm{AmB}$ required to inhibit biofilm development to give MIC at
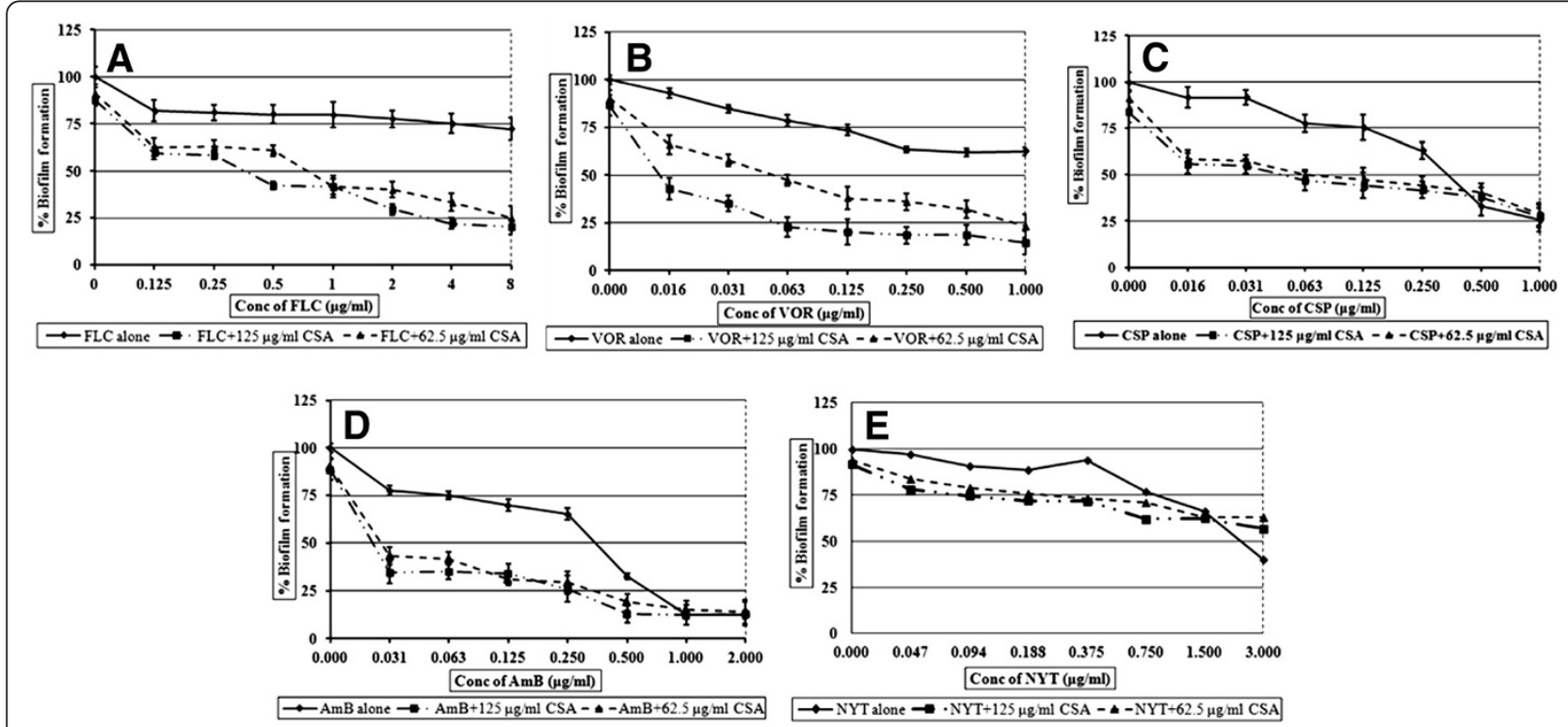

Figure 2 Activity of five antifungal drugs alone and in combination with Cyclosporine A, against biofilm development of $C$. albicans. Percentage of growth was analyzed by comparing relative metabolic activity (RMA) obtained through XTT metabolic assay. A) FLC- CSA; B) VOR- CSA; C) CSP- CSA; D) AmB- CSA; E) NYT- CSA. 
$0.031 \mu \mathrm{g} / \mathrm{ml}$ (Figure 2D). The FIC index of $0.25 \mathrm{sug}$ gested synergism between $\mathrm{AmB}$ and CSA. Combining NYT and CSA did not show any decrease in MIC of the individual drug (Figure 2E), and the FIC index of 0.62 indicated indifference.

\section{Cyclosporine A sensitizes mature biofilms to the various antifungal drugs}

Mature biofilms were completely resistant to FLC and VOR. MIC was obtained at very high i.e. 1024 and $4 \mu \mathrm{g} / \mathrm{ml}$ concentrations of FLC and VOR, respectively. FLC alone was ineffective against mature biofilms, but when combined with $62.5 \mu \mathrm{g} / \mathrm{ml}$ of CSA, synergistic activity (FICI of 0.06) significantly eradicated the biofilms at concentrations as low as $2 \mu \mathrm{g} / \mathrm{ml}$ (Table 1; Figure 3A). While, in presence of $125 \mu \mathrm{g} / \mathrm{ml} \mathrm{CSA}$, MIC of FLC was $0.5 \mu \mathrm{g} / \mathrm{ml}$. Addition of CSA sensitized mature biofilms so that MIC of VOR was obtained at $0.061 \mu \mathrm{g} / \mathrm{ml}$ (Figure 3B). FIC index of 0.14 indicated synergism in this combination. Although CSP alone was effective in biofilm eradication, it required higher concentration compared to that of planktonic cells. One $\mu \mathrm{g} / \mathrm{ml}$ of CSP was required to remove $50 \%$ of biofilm. Combination of CSP-CSA caused eight fold decrease in the MIC to bring it at $0.125 \mu \mathrm{g} / \mathrm{ml}$ (Figure 3C). FIC index for this synergistic drug interaction was calculated to be 0.25 . AmB combination with CSA showed indifference and MIC of CSA-AmB for $24 \mathrm{~h}$ old biofilm was found unchanged compared to $\mathrm{AmB}$ alone (Figure 3D). Addition of CSA did not alter the activity of NYT against biofilms. FIC indices of 0.5 and 0.62 for combinations of CSA with AmB and NYT, respectively, indicated indifference in activity.

\section{Discussion}

Biofilm associated C. albicans infections among immunocompromised patients is a challenge to clinical treatment $[4,8]$. Various studies reported that biofilms formed by $C$. albicans are resistant to most of the commonly used antifungal drugs [10,14]. Various reasons have been proposed to be responsible for the antifungal resistance of $C$. albicans biofilms $[4,8,9]$ including the calcinurine mediated tolerance to the drugs [17]. It is considered as a multi factorial phenomenon resulting due to surface induced gene expression. Hence, combination of drugs with different mode of action may inhibit multiple cellular targets and hence would be a good strategy against biofilms. Combinatorial approach against planktonic form of C. albicans has been studied and was found promising; however, only limited studies are available on biofilms [14,16,17]. Results obtained with planktonic forms may not always work in biofilm setup. Our study is of significance as CSA combination with various antifungal drugs is studied in planktonic as well as biofilm growth forms. Biofilm formation and mature biofilms were found completely resistant to the azoles, FLC and VOR, while CSP, AmB and NYT required high concentrations for preventive activity against biofilms. Resistance to FLC and VOR exhibited by early and late biofilms was totally reverted by the addition of CSA and biofilms became several folds sensitive. Combination of azoles with CSA can be developed
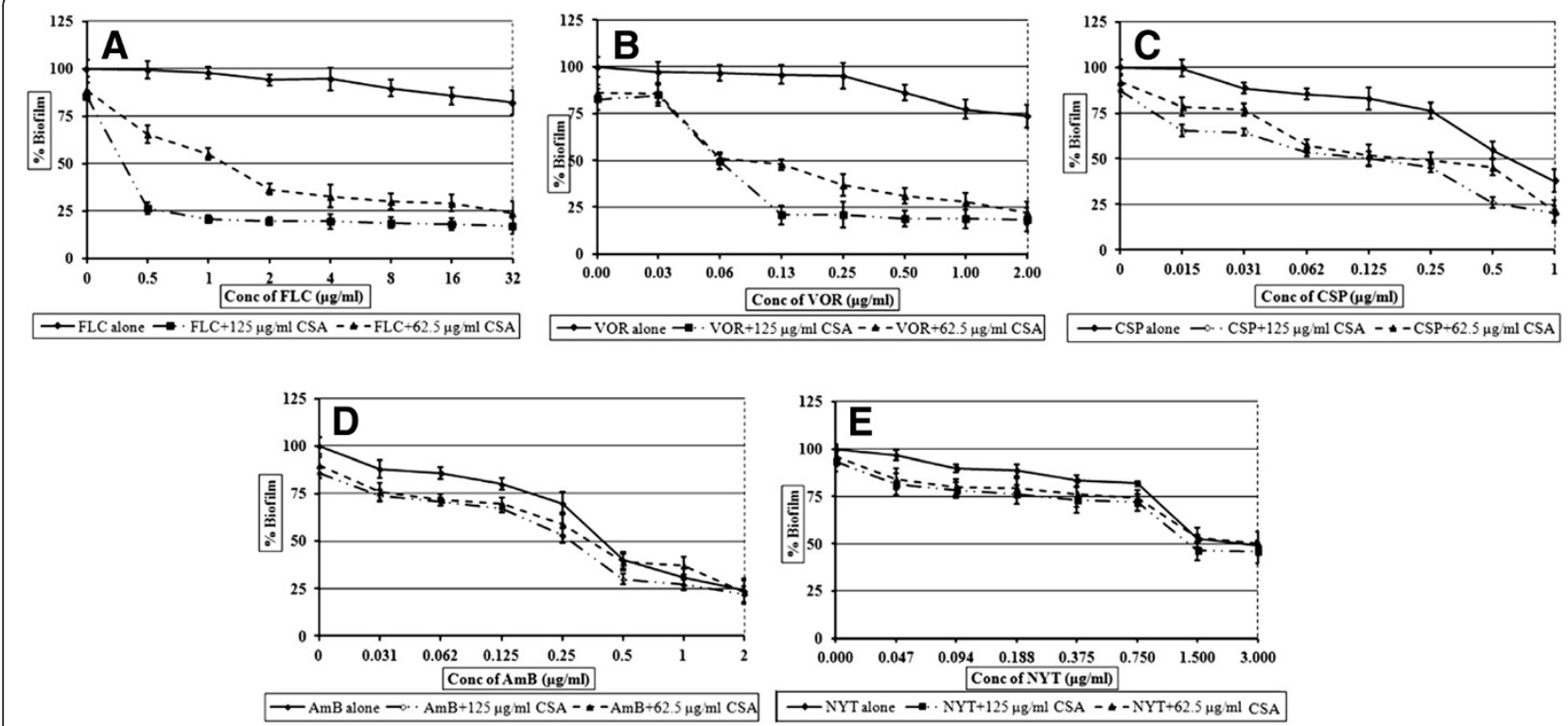

Figure 3 Effect of antifungal drugs alone and in combination with Cyclosporine $A$, on mature biofilms of $C$. albicans. Percentage of growth was analyzed by comparing relative metabolic activity (RMA) obtained through XTT metabolic assay. A) FLC- CSA: B) VOR- CSA; C) CSP- CSA; D) AmB- CSA; E) NYT- CSA. 
as promising anti-biofilm strategy. Similarly increased tolerance to the drugs CSP and AmB in developing biofilms was reverted in presence of CSA, exhibiting low MIC values of CSP and AmB. Lowered antifungal concentrations may be physiologically relevant during treatment of biofilm associated infections. Addition of CSA did not alter sensitivity of mature biofilms to $\mathrm{AmB}$ and NYT. At 62.5 and $125 \mu \mathrm{g} / \mathrm{ml}$, CSA did not have any effect on growth and viability of $C$. albicans. However, in presence of it the MICs of antifungal drugs for planktonic growth of C. albicans were significantly reduced, indicating ability of CSA to act as a chemosensitizer. FIC indices obtained, suggests high synergistic activity of antifungal drugs with CSA. The usefulness of FLC and CSA combinations against C. albicans planktonic and biofilm forms are reported by various workers [17]. However, our study for the first time demonstrates the potential of CSA against planktonic growth, biofilm formation as well as mature biofilms in combination with five antifungal drugs including FLC. Calcineurin is a $\mathrm{Ca}^{2+}$-calmodulin- activated phosphatase which plays important roles in various physiological functions of C. albicans, including morphogenesis, cell wall biosynthesis, antifungal drug resistance and virulence [17]. It is reported to play a direct role in biofilm resistance to fluconazole [17]. CSA is known as a calcineurine inhibitor. Results obtained in this study suggests that CSA mediated inhibition of biofilm specific mechanisms potentiates antifungals against drug resistant biofilms. Increased susceptibility of planktonic cells and reversal of drug resistance in biofilm growth forms after addition of CSA indicates that calcineurine may be playing important role in resistance to FLC, VOR and CSP. However, the exact mechanisms behind CSA mediated synergism with various antifungal drugs are not understood [19]. Outcome of this in vitro study gives insight into use of CSA- antifungal drug combinations for treatment of biofilm associated Candida infections. The antifungal drugs used in this study are also known for their undesirable side effects in humans, as such, reduction in their effective dosages after combination with CSA may be of wide interest. To confirm the utility of these drug combinations in clinics, in vivo studies and clinical trials are necessary.

\section{Conclusions}

The results presented are the systematic information on synergistic activity of CSA with various antifungal drugs against planktonic and biofilm growth of C. albicans. The study for the first time showed that, combination of CSA sensitizes planktonic cells as well as drug resistant biofilms to azoles, polyene and echinocandin antifungal drugs. Further studies in this direction would give insight into an effective strategy for the prophylaxis and treatment of biofilm associated Candida infections.

\section{Abbreviations}

MIC: Minimum inhibitory concentration; MFC: Minimum fungicidal concentration; ATCC: American type culture collection;

MOPS: Morpholinepropanesulfonic acid; FLC: Fluconazole; VOR: Voriconazole; CSP: Caspofungin; AmB: Amphotericin B; NYT: Nystatin; CSA: Cyclosporine A; CLSI: Clinical Laboratory Standards Institute; FICl: Fractional inhibitory concentration index; XTT: 2, 3-bis (2-methoxy-4-nitro-5-sulfo-phenyl)-2Htetrazolium-5-carboxanilide.

\section{Competing interests}

The authors declare that they have no competing interests.

\section{Authors' contributions}

RBS carried out all experimental work, data acquisition and analysis, literature search. NMC and JSR contributed to experiments, writing and manuscript preparation. SMK was responsible for study concept, designing and coordinating the research, supervising the work and revising the manuscript. All authors read and approved the final manuscript.

\section{Acknowledgements}

RBS is thankful to ICMR, New Delhi for fellowship (file no. 80/607/2008/ECD-I) provided to him under ICMR-SRF program.

Received: 14 June 2012 Accepted: 29 September 2012

Published: 4 October 2012

\section{References}

1. Kim J, Sudbery P: Candida albicans, a major human fungal pathogen. J Microbiol 2011, 49:171-172.

2. Espinel-Ingroff A: Novel antifungal agents, targets or therapeutic strategies for the treatment of invasive fungal diseases: a review of the literature (2005-2009). Rev Iberoam Micol 2009, 26:15-22.

3. Pfaller MA, Diekema DJ: Epidemiology of invasive candidiasis: a persistent public health problem. Clin Microbiol Rev 2007, 20:133-163.

4. Chandra J, Mukherjee PK, Hoyer LL, Ghannoum MA: Candida biofilms associated with CVC and medical devices. Mycoses 2012, 55:46-57.

5. Mishra NN, Prasad T, Sharma N, Payasi A, Prasad R, Gupta DK, Singh R: Pathogenicity and drug resistance in Candida albicans and other yeast species. Acta Microbiol Immunol Hungar 2007, 54:201-235.

6. White TC, Holleman S, Dy F, Mirels LF, Stevens DA: Resistance mechanisms in clinical isolates of Candida albicans. Antimicrob Agents Chemother 2002, 46:1704-1717

7. Ali I, Khan FG, SuriK A, Gupta BD, Satti NK, Dutt P, Afrin F, Qazi GN, Khan IA: In vitro antifungal activity of hydroxychavicol isolated from Piper betle $\mathrm{L}$. Ann Clin Microbiol Antimicrob 2010, 9:7.

8. Ramage G, Saville SP, Thomas DP, Lopez-Ribot JL: Candida biofilms: an update. Eukaryotic Cell 2005, 4:633-638.

9. Baillie GS, Douglas LJ: Matrix polymers of Candida albicans biofilms and their possible role in biofilm resistance to antifungal agents. J Antimicrob Chemother 2000, 46:397-403.

10. Lewis RE, Kontoyiannis DP: Rationale for combination antifungal therapy Pharmacother 2001, 21:149S-164S.

11. Lewis RE, Diekema DJ, Messer SA, Pfaller MA, Klepser ME: Comparison of Etest, chequerboard dilution and time-kill studies for the detection of synergy or antagonism between antifungal agents tested against Candida species. J Antimicrob Chemother 2002, 49:345-351.

12. Ghannoum MA, Fu Y, Ibrahim AS, Mortara LA, Shafiq MC, Edwards JE, Criddle RS: In vitro determination of optimal antifungal combinations against Cryptococcus neoformans and Candida albicans. Antimicrob Agents Chemother 1995, 39:2459-2465.

13. Baddley JM, Pappas PG: Combination antifungal therapy for the treatment of invasive yeast and mold infections. Curr Infect Dis Rep 2007 9:448-456.

14. Tobudic S, Kratzer C, Lassnigg A, Presterl E: Antifungal susceptibility of Candida albicans in biofilms. Mycoses 2012, 55:199-204.

15. Andes D, Nett J, Oschel P, Albert R, Marchillo K, Pitula A: Development and characterization of an in vivo central venous catheter Candida albicans biofilm model. Infect Immun 2004, 72:6023-6031. 
16. Bachmann SP, Ramage G, VandeWalle K, Patterson TF, Wickes BL, Lo'pezRibot JL: Antifungal combinations against Candida albicans biofilms in vitro. Antimicrob Agents Chemother 2003, 45:999-1007.

17. Uppuluri P, Nett J, Heitman J, Andes D: Synergistic effect of calcineurin inhibitors and fluconazole against Candida albicans biofilms. Antimicrob Agents Chemother 2008, 52:1127-1132.

18. Marchetti O, Moreillon P, Glauser MP, Bille J, Sanglard D: Potent Synergism of the combination of fluconazole and cyclosporine in Candida albicans. Antimicrob Agents Chemother 2000, 44:2373-2381.

19. Marchetti O, Moreillon P, Entenza JM, Vouillamoz J, Glauser MP, Bille J, Sanglard D: Fungicidal synergism of fluconazole and cyclosporine in Candida albicans is not dependent on multidrug efflux transporters encoded by the CDR1, CDR2, CaMDR1, and FLU1 genes. Antimicrob Agents Chemother 2003, 47:1565-1570

20. Clinical and Laboratory Standards Institute: Reference method for broth dilution antifungal susceptibility testing of yeast: Approved standard CLSI Document M27-A3. Wayne, Pa: Clinical Laboratory Standards Institute; 2008

21. Johnson MD, MacDougall C, Ostrosky-Zeichner L, Perfect JR, Rex JH: Combination antifungal therapy. Antimicrob Agents Chemother 2004, 48:693-715.

22. Odds FC: Synergy, antagonism, and what the chequerboard puts between them. J Antimicrob Chemother 2003, 52:1

23. Shinde RB, Raut JS, Karuppayil SM: Biofilm formation by Candida albicans on various prosthetic materials and its fluconazole sensitivity: A kinetic study. Mycoscience 2012, 53:220-226.

doi:10.1186/1476-0711-11-27

Cite this article as: Shinde et al:: Sensitization of Candida albicans

biofilms to various antifungal drugs by cyclosporine A. Annals of Clinical Microbiology and Antimicrobials 2012 11:27.

\section{Submit your next manuscript to BioMed Central and take full advantage of:}

- Convenient online submission

- Thorough peer review

- No space constraints or color figure charges

- Immediate publication on acceptance

- Inclusion in PubMed, CAS, Scopus and Google Scholar

- Research which is freely available for redistribution 